\title{
T63 induces apoptosis in nasopharyngeal carcinoma cells through mitochondrial dysfunction and inhibition of PI3K/Akt signaling pathway
}

\author{
Qin Liu $^{1 \#}$, Wei Chen ${ }^{2,3,4 \#}$, Huiling Yang ${ }^{5}$ \\ ${ }^{1}$ Department of Science and Technology, Chongqing Traditional Chinese Medicine Hospital, Chongqing, China; ${ }^{2}$ Department of Colorectal \\ Surgery, ${ }^{3}$ Guangdong Provincial Key laboratory of Colorectal and Pelvic Floor Disease, ${ }^{4}$ Guangdong Research Institute of Gastroenterology, The \\ Sixth Affiliated Hospital of Sun Yat-sen University, Guangzhou, China; ${ }^{5}$ Department of Pathophysiology, Zhongshan School of Medicine, Sun Yat- \\ sen University, Guangzhou, China \\ Contributions: (I) Conception and design: All authors; (II) Administrative support: H Yang; (III) Provision of study materials or patients: Q Liu; (IV) \\ Collection and assembly of data: W Chen; (V) Data analysis and interpretation: Q Liu, W Chen; (VI) Manuscript writing: All authors; (VII) Final \\ approval of manuscript: All authors. \\ "These authors contributed equally to this work. \\ Correspondence to: Huiling Yang. Department of Pathology and Pathophysiology, Zhongshan School of Medicine, Sun Yat-sen University, Guangzhou \\ 510080, China. Email: 277946545@qq.com.
}

Background: Nasopharyngeal carcinoma (NPC) is a common malignant tumor in china. T63 is one of
novel curcumin analogues, which reduces the tumorigenic potential effectively.
Methods: We investigated the mechanism of anti-cancer activity on NPC cells treatment with T63 for the
first time. Cell viability was monitored using the method of MTT and colony formation assay. Morphological
changes observed by fluorescence microscope with Hoechst 33342 staining. The cell cycle, the rates of cell
apoptotic and mitochondrial membrane potential were identified by flow cytometry, and apoptotic proteins
were identified by western blot analysis.

Results: In our study, we found a significant decrease in the number of viable cells and in colony formation abilities of NPC cells (CNE2 and CNE2R) after 24, 48 and $72 \mathrm{~h}$ treatment with T63. T63 promoted morphologic changes of apoptosis and increased apoptotic rate. T63 promoted also cell cycle arrest of $\mathrm{G}_{2} / \mathrm{M}$ phases followed by decreased cell viability in CNE2 and CNE2R after $48 \mathrm{~h}$. Then the loss of the mitochondrial membrane potential and release of cytochrome-c were demonstrated. Western blotting analysis found a decrease in Bcl-2/Bax ratio and activation of caspase-8, -9, -3 and PARP. And the changes of PTEN and p-Akt ${ }^{\mathrm{p} 473}$ suggested PTEN/PI3K/Akt might be an important signaling pathway in the anticancer role of T63.

Conclusions: T63 definitely induced apoptosis in radiosensitive and radioresistant NPC cell lines. But the apoptotic effect was stronger on radioresistant cells than that on radiosensitive cells through activation of mitochondria-mediated apoptotic pathway.

Keywords: Nasopharyngeal carcinoma (NPC); radioresistance; apoptosis; Mitochondrial pathway; Akt

Submitted Mar 25, 2020. Accepted for publication Jul 14, 2020.

doi: $10.21037 /$ tcr-20-1677

View this article at: http://dx.doi.org/10.21037/tcr-20-1677

\section{Introduction}

Nasopharyngeal carcinoma (NPC) is a common malignant tumor in china, related with Epstein-Barr virus infection, dietary, genetic predisposition and environmental factors (1).
Radiotherapy is the first choice for NPC patients, however the five-year survival rate is only about $25 \%$ because of radioresistance (2).

During the past decade, emerging evidence has suggested curcumin was a promising drug in cancer prevention and 
therapy. Furthermore, some investigations have revealed curcumin was a chemosensitizer and radiosensitizer in many cancers, including breast cancer, colon and gastric cancer, pancreatic cancer, head and neck cancer, brain cancer in vivo and in vitro (3-5). But the most important defect of curcumin is its low bioavailability in humans $(6,7)$. To improve the bioavailability of curcumin, novel curcumin analogue has been evaluated. T63 is one of the new 4-arylidene curcumin analogues (Figure 1A), which has been reported by Qiu et al. (8). It has demonstrated that the tumorigenic potential of lung cancer cells was affected by T63 (9).

In our study, we investigated the anti-cancer activity of T63 on NPC cells for the first time. We also explored its significant effect on radioresistant NPC cell line (CNE2R) in order to suggest T63 could be a potential drug for NPC patients with radioresistance. The results of this study could provide scientific basis and technology support for NPC therapy.

\section{Methods}

\section{Chemicals and reagents}

T63 was synthesized by the School of Pharmaceutical Sciences, Sun Yat-sen University (Guangzhou, China). Propidium iodide (PI), 3-(4,5-Dimethyl-2-thiazolyl)2,5-diphenyl-2H-tetrazolium bromide (MTT) and Rhodamine 123 were obtained from Sigma-Aldrich Chemical Company (Sigma-Aldrich, St. Louis, MO). Hoechast33342 was purchased from Molecular Probes (Life Technologies, USA). The fluorescein isothiocyanate-labeled AnnexinV/propidium iodide Apoptosis Detection Kit was purchased from Roche (Roche Diagnostics, Indianapolis, USA). The following proteins were evaluated by western blotting: Bcl-2 (Cell Signaling Technology Cat\# 15071, RRID: AB_2744528), Bax (Cell Signaling Technology Cat\# 2774, RRID: AB_490806), Caspase-8, -9, -3 (\#4790, RRID: AB_10545768); \#9502, RRID: AB_2068621; \#9662, RRID: AB_331439; Cell Signaling, USA), PTEN (Cell Signaling Technology Cat\# 9552, RRID: AB_10694066), $\mathrm{p}-\mathrm{Akt}^{\mathrm{p} 473}$ (Antibodies-Online Cat\# ABIN461540, RRID: AB_10805010), Akt (Cell Signaling Technology Cat\# 9272, RRID: AB_329827), PARP (Cell Signaling Technology Cat\# 7858, RRID: AB_1264143), Cyclin D1 (Cell Signaling Technology Cat\# 2922, RRID: AB_2228523), p21 (Cell Signaling Technology Cat\# 2947, RRID: AB_823586), p27 (Cell Signaling Technology Cat\# 3686, RRID:
AB_2077850) and $\beta$-actin (Multi Sciences Cat\# 70-ab008100, RRID: AB_2750915). The ECL Western blot analysis reagents were purchased from Pierce Biotech (Rockford, IL, USA).

\section{Cell culture}

Two kinds of NPC cell lines (CNE2 and the stable radioresistant NPC cell line CNE2R) were obtained from Cancer Center, Sun Yat-sen University (Guangzhou, China) and our lab (10), cultured in RPMI1640 medium supplemented with $10 \%$ FBS, and incubated under conditions of $5 \% \mathrm{CO}_{2}$ at $37^{\circ} \mathrm{C}$.

\section{Cell viability assay}

The cultured cells in the 96-well microplates (6,000 cells/well) were treated with various concentrations $(0-1.0 \mu \mathrm{M})$ of T63, and incubated for 24, 48, and $72 \mathrm{~h}$. Then, cells from each well were solubilized using $150 \mu \mathrm{L}$ DMSO after incubation with the MTT reagent for $4 \mathrm{~h}$, and absorbance of the samples was measured using a microplate reader at a wavelength of $570 \mathrm{~nm}$.

\section{Colony formation assay}

For the colony formation assay, the cells treated with 0.05 , 0.1 and $0.2 \mu \mathrm{M}$ T63 for $48 \mathrm{~h}$ were plated onto cell culture dishes, with a diameter of $6 \mathrm{~cm}$, at a density of 500 cells/well and maintained for $14 \mathrm{~d}$. Visible colonies (containing $>50$ cells) were identified through Giemsa staining.

\section{Morphological changes}

The cells were plated into 6-well plates at a density of $2 \times 10^{5}$ cells/well overnight, and then divided into four groups (control, $0.1 \mu \mathrm{M}$ group, $0.5 \mu \mathrm{M}$ group, $1.0 \mu \mathrm{M}$ group). After $48 \mathrm{~h}$, cells were fixed with methanol, then stained with $10 \mu \mathrm{g} / \mathrm{mL}$ Hoechst33342 for $15 \mathrm{~min}$ and washed by PBS. A fluorescence microscope (Leica DMI4000B, Germany) was used to observe apoptotic morphologic changes.

\section{Flow cytometric analysis of cell cycle and apoptosis}

CNE2 and CNE2R cells $\left(3 \times 10^{5}\right.$ cells/well $)$ were treated with different concentrations of T63 $(0.1,0.3$ and $0.5 \mu \mathrm{M})$ in 6-well plates for $24 \mathrm{~h}$. The treated cells were harvested, 
fixed overnight in cold $70 \%$ ethanol at $4{ }^{\circ} \mathrm{C}$, washed twice with chilled PBS, incubated with $100 \mu \mathrm{L}$ RNAase (final concentration, $20 \mu \mathrm{g} / \mathrm{mL}$ ) at $37^{\circ} \mathrm{C}$ for $30 \mathrm{~min}$, and stained using $400 \mu \mathrm{L}$ of propidium iodide (PI; final concentration, $50 \mu \mathrm{g} / \mathrm{mL}$ ) for $30 \mathrm{~min}$. The labeled cells were analyzed by flow cytometry using the ModFit Software (Verity Software House Inc., USA). Additionally, the fluorescein isothiocyanate-labeled AnnexinV/propidium iodide Apoptosis Detection Kit was used to analyze the apoptosis of CNE2 and CNE2R cells treated with T63 according to the manufacturer's instructions. A FACScan flow cytometer with The Cell Quest software was used for data acquisition and analysis.

\section{Flow cytometric analysis of mitochondrial membrane potential}

Mitochondrial membrane potential was measured using flow cytometry with the fluorescent probe rhodamine 123 (Rh123). Rh123 accumulated in normal mitochondrial due to its high negative charge. Loss of mitochondrial transmembrane potential led to the release of Rh123 and a reduction in its fluorescence intensity. Rh123 was prepared in PBS to a final concentration of $5 \mu \mathrm{g} / \mathrm{mL}$. Exponentially growing CNE2 and CNE2R cells were seeded into 6-well plates at a density of $2 \times 10^{5}$ cells overnight. T63 was added at different final concentrations. In control group, equal volume of RPMI1640 medium was added. After incubating for $16 \mathrm{~h}$, cells were harvested by trypsin and washed with PBS. The Rh123 $(5 \mu \mathrm{g} / \mathrm{mL})$ were added into the cells and incubated at $37{ }^{\circ} \mathrm{C}$ in an incubator containing $5 \% \mathrm{CO}_{2}$ for $30 \mathrm{~min}$. Then samples were centrifuged and washed with cold PBS twice. The samples were resuspended in $1 \mathrm{~mL}$ PBS and analyzed by flow cytometry. The experiment was repeated three times.

\section{Western blotting}

Western blotting was used for analyzing specific proteins. NPC cells were cultured in complete medium for $12 \mathrm{~h}$ followed by different concentrations of T63 $(0.4,0.8$, and $1.6 \mu \mathrm{M})$. Then the incubation was carried out for $48 \mathrm{~h}$. After the indicated incubation period, cells were harvested by scraping from culture dishes, lysed in $1 \times$ sampling buffer (Cell signaling Technology, Danvers, MA) with protease inhibitor cocktail (Roche) and collected by centrifugation. The samples were loaded on SDS-polyacrylamide gradient gels $(8 \%, 10 \%, 12 \%$ and $15 \%)$ (Bio-Rad, Hercules, CA), and electrophoretically transferred to polyvinylidene fluoride (PVDF) membranes (EMD Millipore, Billerica, USA). Membranes were blocked with fat-free milk powder (Roche) $(5 \%, w / v)$ and Tween $20(1 \%, w / v)$ in TBS-T for $1 \mathrm{~h}$. Each membrane was incubated with primary antibodies.

\section{Statistical analysis}

Each experiment was performed at least in triplicates. The data are presented as the mean \pm SD. All statistical analyses were performed using the SPSS 11.0 software and $\mathrm{P}$ values of $<0.05$ were considered to be statistically significant.

\section{Results}

\section{Effects of T63 on cell viability}

As shown in Figure 1B, after treatment with T63 for 24, 48 and $72 \mathrm{~h}$, IC50 values were $1.62 \pm 0.11,0.51 \pm 0.09,0.34 \pm$ $0.06 \mu \mathrm{M}$ for $\mathrm{CNE} 2$, and $1.53 \pm 0.09,0.37 \pm 0.04,0.14 \pm$ $0.04 \mu \mathrm{M}$ for CNE2R. We demonstrated that T63 decreased the viabilities of CNE2 and CNE2R cells in a dose- and time-dependent manner $(\mathrm{P}<0.05$ and $\mathrm{P}<0.01$, respectively). The MTT assay showed that T63 significantly inhibited the viabilities of CNE2 and CNE2R cells (Figure 1C,D). Clearly, after treatment with T63 for $48 \mathrm{~h}$, the cytotoxicity in CNE2R cells was stronger than that in CNE2 cells. Consistent with the MTT results, colony formation assay (Figure 2A) showed that T63 significantly inhibited the focus numbers of both CNE2 and CNE2R cells, but there were no significant differences between CNE2 and CNE2R.

\section{Effect of T63 on morphologic changes}

The morphologic changes of cells treated with different concentrations of T63 $(0.1,0.5$, and $1.0 \mu \mathrm{M})$ were observed under fluorescence microscope by Hochest33342 staining. As shown in Figure 2B, typical morphological changes, such as chromatin condensation and the formation of apoptotic bodies, appeared after treatment with $0.5 \mu \mathrm{M}$ T63 for $48 \mathrm{~h}$, whereas the vehicle treated cells did not show evident apoptotic morphological changes.

\section{Effects of T63 on cell cycle and apoptosis}

DNA cell cycle analysis was performed to estimate the effect of T63 on the distribution of CNE2 and CNE2R cells in 
A<smiles>COc1cc(C=C(C(=O)/C=C/c2ccc(OC)c(OC)c2)C(=O)/C=C/c2ccc(OC)c(OC)c2)ccc1O</smiles>

C

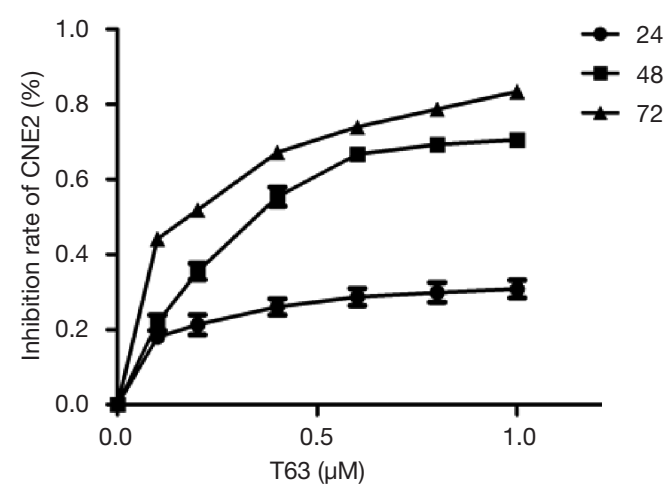

B

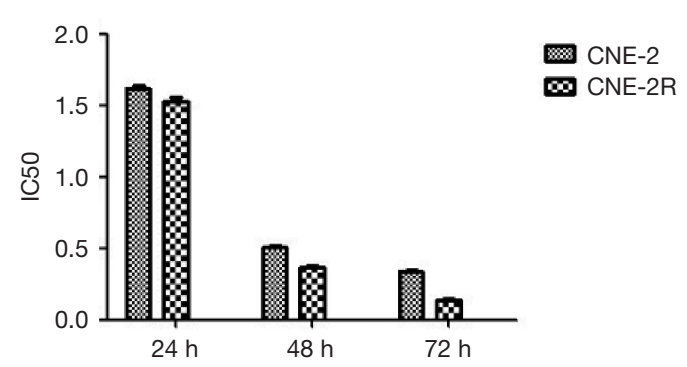

D

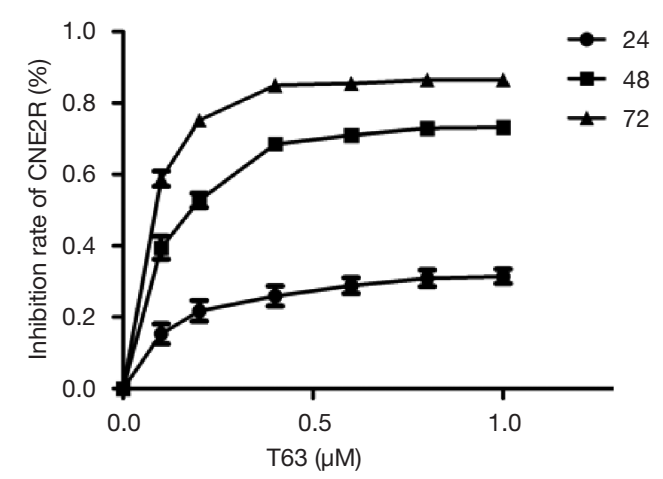

Figure 1 Effects of T63 on cell viability. (A) Chemical structure of T63. (B) IC50 values of T63 on both cell lines were shown by columns. (C,D) CNE2 and CNE2R cells were incubated with various concentrations of T63 for 24, 48 and 72 h, and cell viabilities were quantified by MTT assay. Data points were presented as mean \pm SD.

cell cycle. As shown in Figure 3A, compared with control, both CNE2 and CNE2R cells exhibited accumulation of cells in the $G_{2} / M$ phase accompanied by a decrease in $S$ phase in a dose-dependent way upon T63 treatment. The percentage of cells in the $G_{2} / M$ phase increased six-fold when cells were treated with $0.5 \mu \mathrm{g} / \mathrm{mL}$ of $\mathrm{T} 63$, and there was no significant difference between CNE2 and CNE2R cells.

The morphologic changes suggested that T63 induced cell apoptosis. We performed AnnexinV-FITC/PI double staining and the population of apoptotic cells was analyzed by flow cytometry. As shown in Figure 3B, 6.42\% $\pm 0.31 \%$ cells were positive for AnnexinV-FITC staining in control group, while after treatment with T63 apoptotic cells increased to $10.41 \% \pm 0.44 \%, 12.93 \% \pm 0.75 \%$ and $14.62 \% \pm 0.37 \%$ at $0.1,0.3$ and $0.5 \mu \mathrm{M}$ respectively $(\mathrm{P}<0.05)$. T63 induced more effective apoptosis in CNE2R than CNE2. The apoptotic rate increased from $7.20 \% \pm 0.47 \%$ to $15.26 \% \pm 0.53 \%, 22.48 \% \pm 1.34 \%$ and $44.94 \% \pm 1.92 \%$ at 0.1 , 0.3 and $0.5 \mu \mathrm{M}$ T63 respectively $(\mathrm{P}<0.05)$.

\section{Effect of T63 on mitochondrial membrane potential}

We used Rh123, which accumulated within mitochondria in a potential-dependent manner to further verify T63 induced a loss of mitochondrial membrane potential. As shown in Figure 3C, treatment with different concentrations of T63 $(0.1,0.3$ and $0.5 \mu \mathrm{M})$ resulted in a dose-dependent decrease $(\mathrm{P}<0.05$ and $\mathrm{P}<0.01$, respectively) in the fluorescence density. Collectively, the data suggested that T63 induced apoptosis in both CNE2 and CNE2R cells through disruption of the mitochondrial membrane potential and a significant difference was found between CNE2 and CNE2R cells $(\mathrm{P}<0.05)$.

\section{Effect of T63 on apoptotic patbways}

We performed western Blotting and detected some apoptotic proteins in both cells after treatment with T63 for $48 \mathrm{~h}$. As shown in Figure 4, we found that the expression level of cleaved PARP increased significantly. The 
A

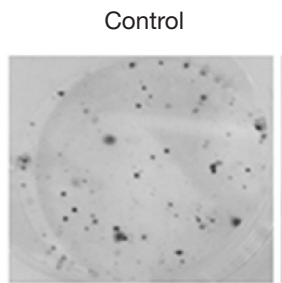

$0.05 \mu \mathrm{M}$
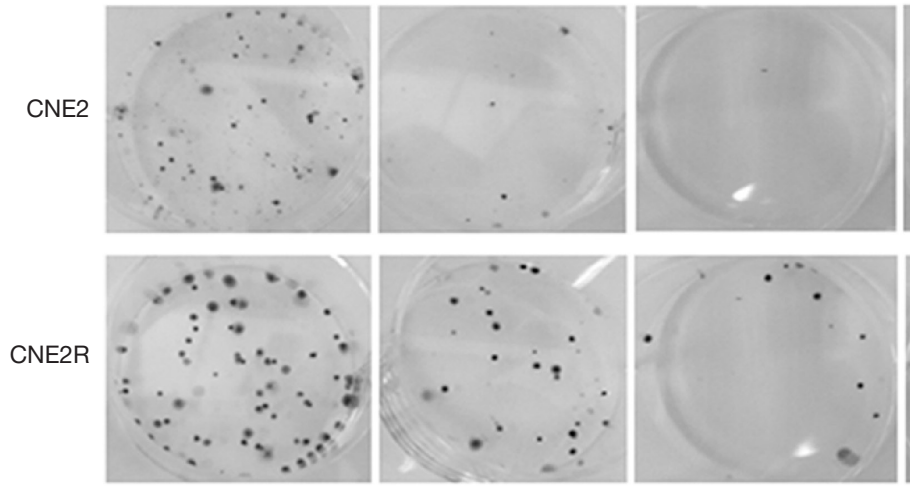

$0.1 \mu \mathrm{M}$
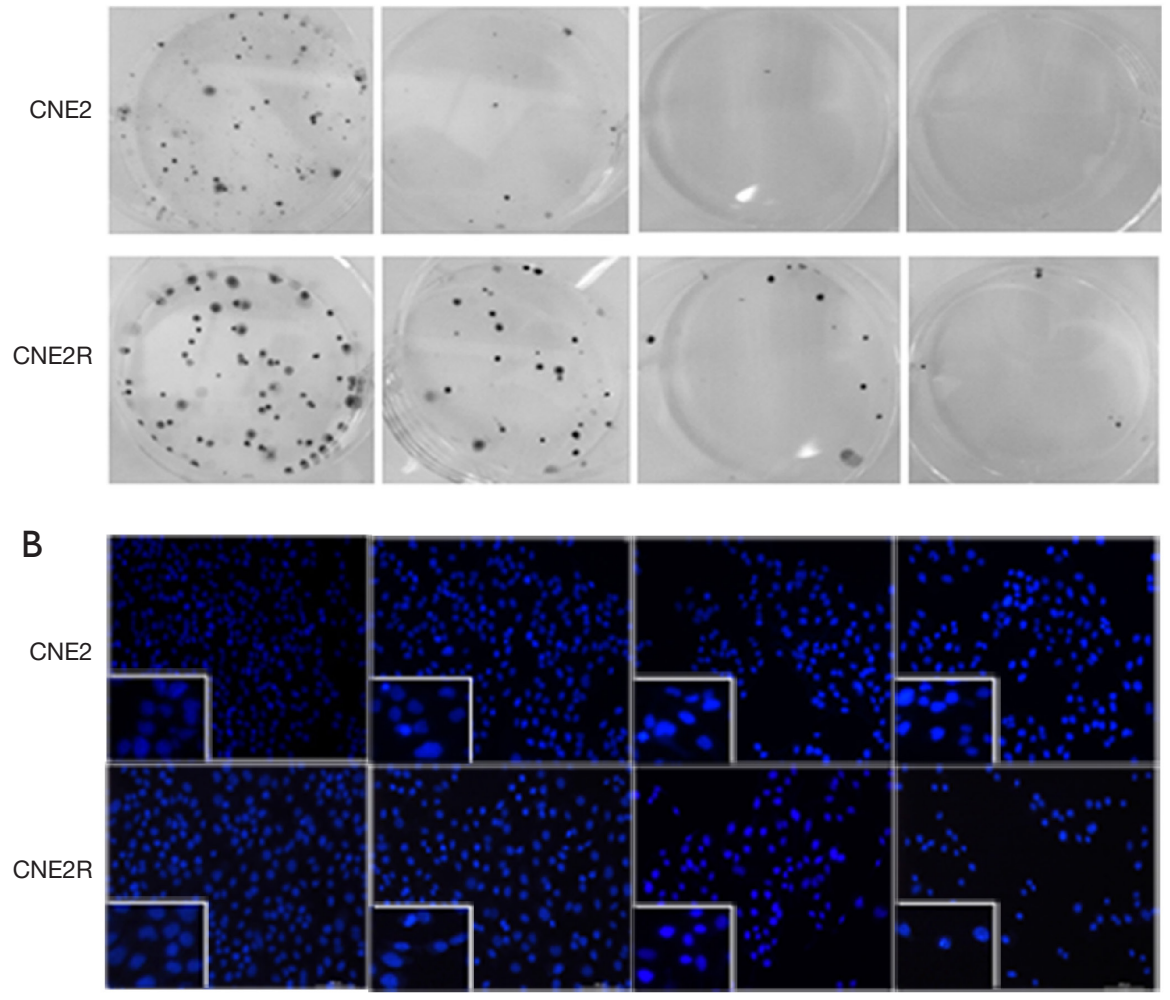
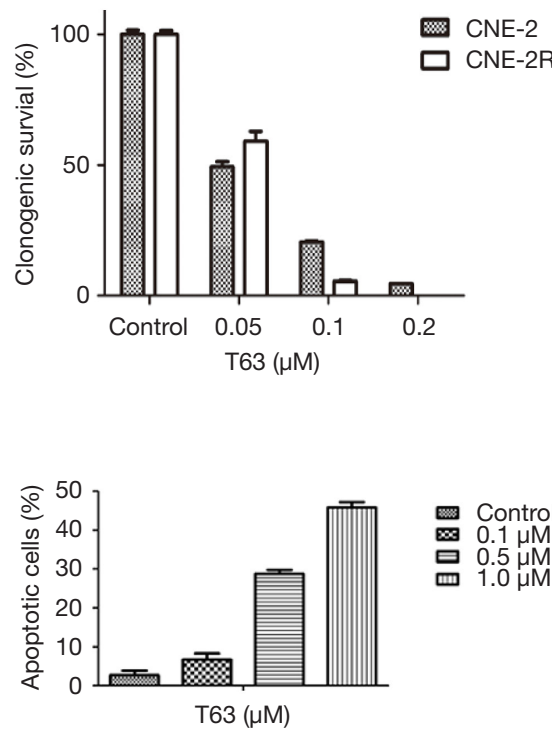

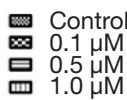

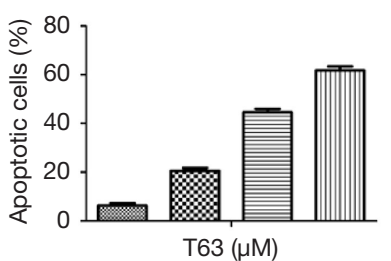

Figure 2 Effect of T63 on colony-forming efficiency and morphologic changes of NPC cell lines. (A) Effects of T63 on colony-forming efficiency of NPC cell lines. The pictures showed representative results of colony formation assays with CNE2 and CNE2R cells. Data were presented in histogram as means \pm SD. The Student's $t$-test was performed to compare the rates of two cell lines' colony formation. (B) Effects of T63 on morphologic changes of NPC cell lines. Hoechst33342 assay of CNE2 and CNE2R cells treated with T63. Samples were visualized under fluorescence microscope $(\times 20)$. For quantification, Hoechst-positive nuclei were count (at least 300 cells were counted for each condition). On the right, the quantification of apoptotic cells was shown. NPC, nasopharyngeal carcinoma.

cytochrome-c in the cytosol also increased. Then we found levels of procaspase- 8 , procaspase- 9 , and procaspase- 3 decreased in a dose-dependent way. And the level of cleaved caspase-3, -8, -9 enhanced remarkably as the same manner.

\section{Effect of T63 on PTEN/PI3K/Akt pathway}

Based on our experimental results and previously available data in literature, some proteins involved in the T63mediated induction of apoptosis were investigated. As shown in Figure 5, the levels of the anti-apoptotic protein, Bcl-2 decreased in CNE2 and CNE2R cells treated with T63, whereas the level of the pro-apoptotic protein Bax increased. Thus the ratio of $\mathrm{Bcl}-2 / \mathrm{Bax}$ decreased after treatment with T63. T63 treatment resulted in an increase of PTEN in CNE2R and inhibition of $\mathrm{p}-\mathrm{Akt}^{\mathrm{p} 473}$ for both NPC cell lines. The levels of Cyclin D1 was found to be significantly inhibited in cells with T63, while the levels of p21 and p27 were increased (Figure 6).

\section{Discussion}

To improve the anticancer effect of curcumin, Qiu et al. identified the new 4-arylidene curcumin analogue, T63. It had some wonderful qualities comparing with the curcumin, such as low micromolar concentrations, good anticancer potential and bioavailability. Surprisingly, T63 exhibited thirtyfold higher in inhibition potency against lung cancer cells than curcumin (8). T63 significantly suppressed the growth of A549 lung cancer xenograft tumors, associated 

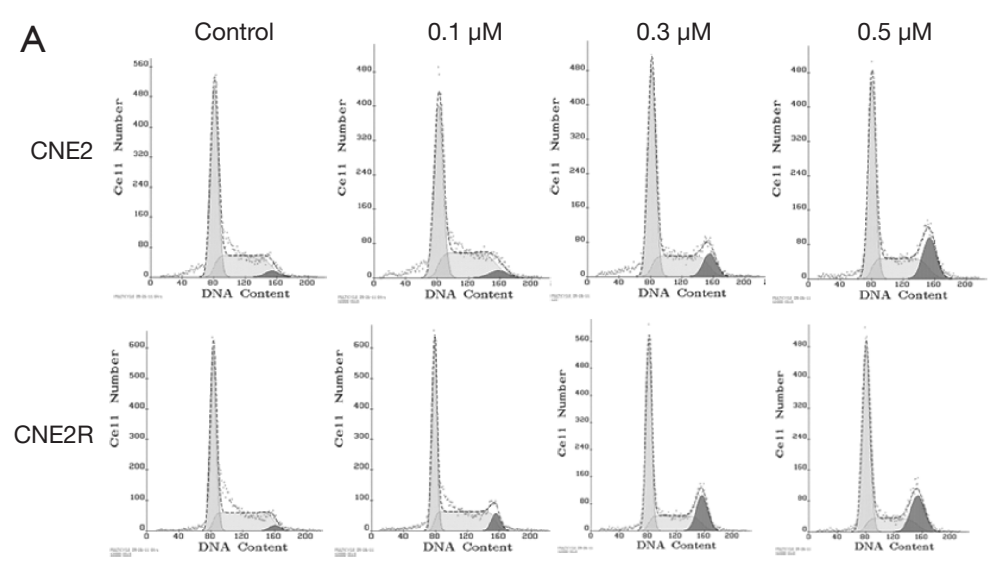

B
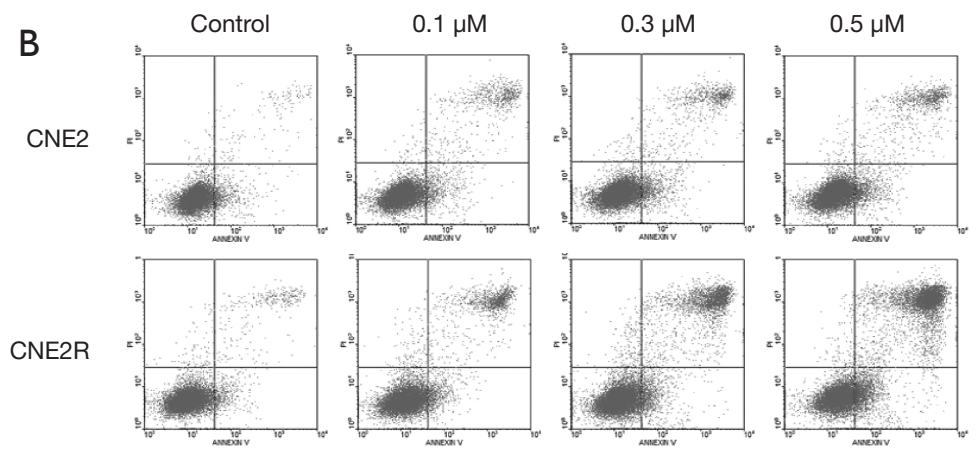

C
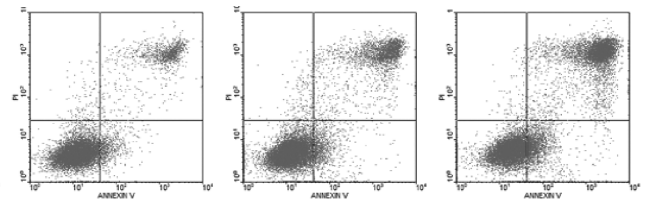

$0.1 \mu \mathrm{M}$
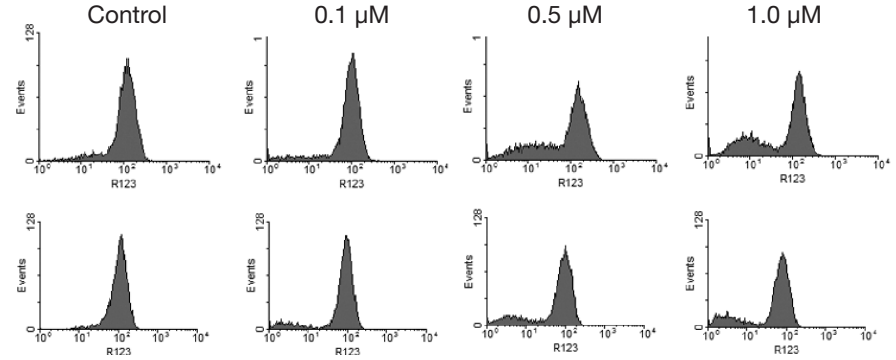
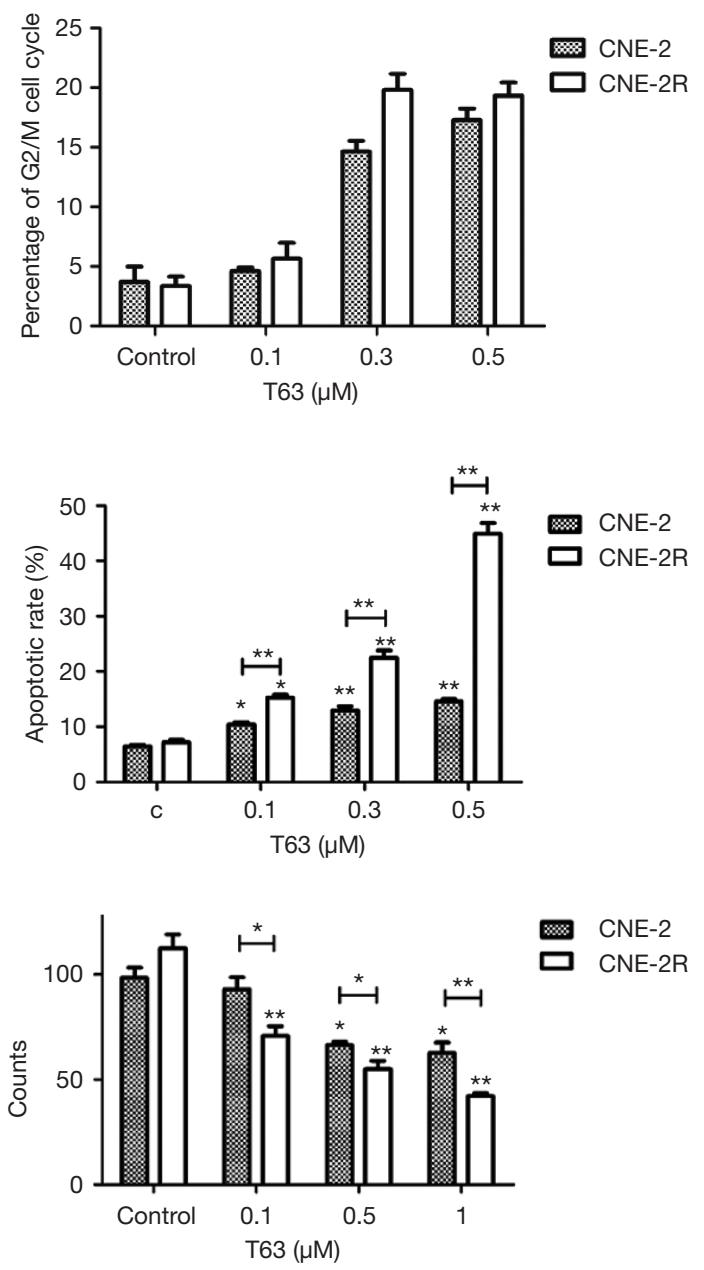

Figure 3 Effects of T63 on cell cycle and apoptosis. (A) CNE2 and CNE2R cells were treated with various concentrations T63 for 24 h. The G2/M cycle arrest was found in CNE2 and CNE2R cells by flow cytometry. On the right, the percentage of G2/M phase cells in CNE2 and CNE2R were shown. (B) The results showed increases in apoptosis percentage in CNE2 and CNE2R cells by AnnexinV-FITC/PI staining. On the right, the quantification of apoptosis percentage was shown analysed by flow cytometry. Data represented three independent experiments, mean \pm SD. (C) Rh123 staining of CNE2 and CNE2R cells treated with different concentrations T63 for 12 h. On the right, means of mitochondrial membrane potential measured by flow cytometry was shown. The Student's $t$-test was performed to compare the rates of two cell lines, and one-way analysis of variance when more than two groups in different concentrations; *, $\mathrm{P}<0.05$ or **, $\mathrm{P}<0.01$.

with proliferation suppression and apoptosis induction in tumor tissues, without inducing any notable major organrelated toxicity (9). T63 exhibited significantly improved potency in blocking the nuclear factor $\mathrm{kB}$ pathway by both in vivo and in vitro kinase assays and pathway analysis (10). We supposed T63 might be a promising anticancer agent with other cancers. Till now, there was no report to suggest its anticancer effect on NPC cells. The mechanisms of T63 need to be explored for NPC cells.

As we all known, curcumin exhibits significant anticancer effect on many tumors in vivo and in vitro. Lin et al. found that the $\mathrm{IC}_{50}$ value of curcumin on human NPC was $50 \mu \mathrm{M}$ for $48 \mathrm{~h}$ (11). It also reported that pretreatment with $3.5 \mu \mathrm{M}$ curcumin can decrease the cell counts by clonogenic assay at 2.5 Gy of radiation, although this concentration did not decrease the ability to form colonies in the absence 

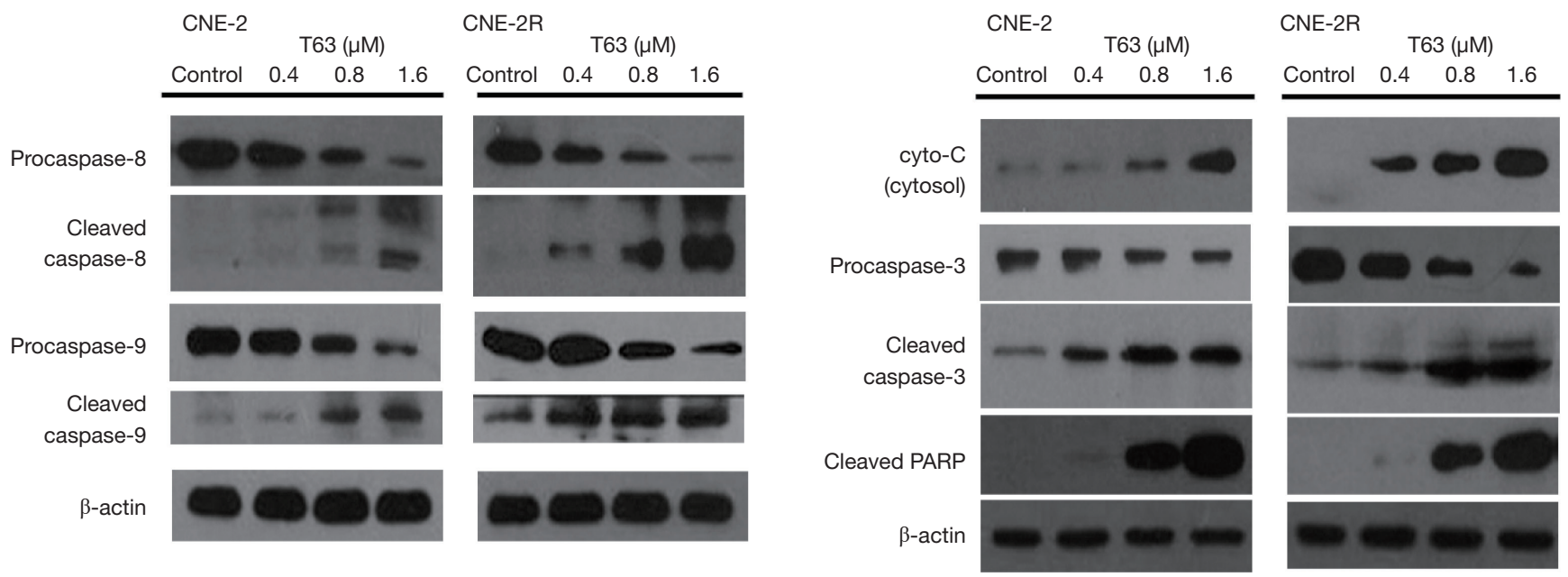

Figure 4 Western blotting measured apoptosis-related proteins including $55 \mathrm{kDa}$ procaspase- $8,18 \mathrm{kDa}$ and $10 \mathrm{kDa}$ cleaved caspase- 8 , $45 \mathrm{kDa}$ procaspase-9, $35 \mathrm{kDa}$ cleaved caspase-9, $15 \mathrm{kDa}$ cytochrome-c, $32 \mathrm{kDa}$ procaspase-3, $19 \mathrm{kDa}$ and $17 \mathrm{kDa}$ cleaved caspase-3 and $89 \mathrm{kDa}$ cleaved-PARP in CNE2 and CNE2R cells after T63 treatment at different concentrations for $48 \mathrm{~h} ; 42 \mathrm{kDa} \beta$-actin was used as an internal control. The student's $t$-test was performed to compare the rates of two cell lines' colony formation, and one-way analysis of variance when more than two groups.
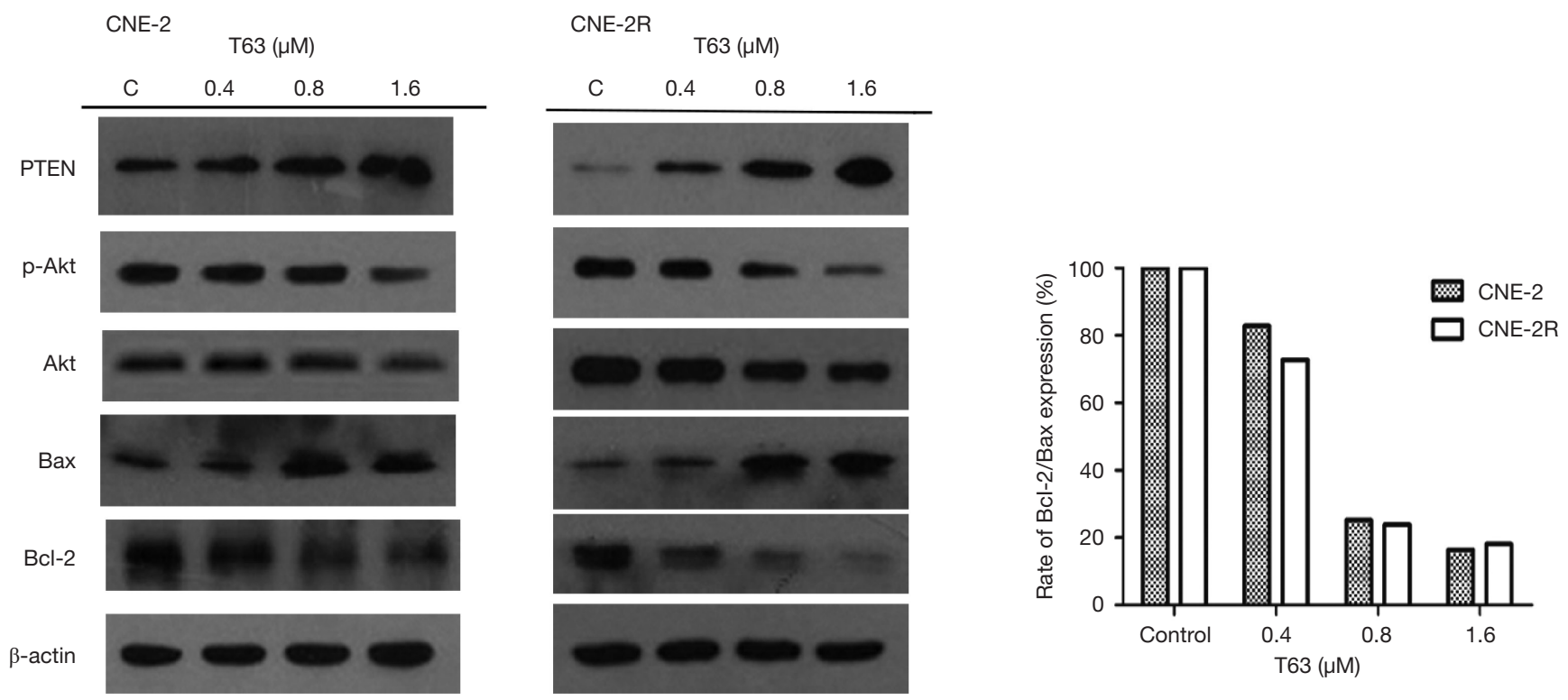

Figure 5 Western blotting analysis of 55 kDa PTEN, 57kDa Akt, 57 kDa p-Akt, 21 kDa Bax and 26 kDa Bcl-2 in CNE2 and CNE2R cells were detected as shown. On the right, ratio changes of Bcl-2/Bax with their densities in Western blotting were presented as column.

of radiation (12). In our study, T63 exerted good growthinhibitory effect in human $\mathrm{NPC}$, and the $\mathrm{IC}_{50}$ values of CNE2 and CNE2R cells were 0.51 and $0.37 \mu \mathrm{M}$ respectively for $48 \mathrm{~h}$. T63 exhibited obviously high inhibition potency in NPC cells, especially of radioresistant cells.

T63 may contribute to the accumulation of $\mathrm{p} 21$ and $\mathrm{p} 27$, which binds and inactivates the Cyclin D-CDK complexes, and then leads to cell cycle arrest in the G0/G1 phase and subsequent apoptosis. Koo et al. demonstrated that 


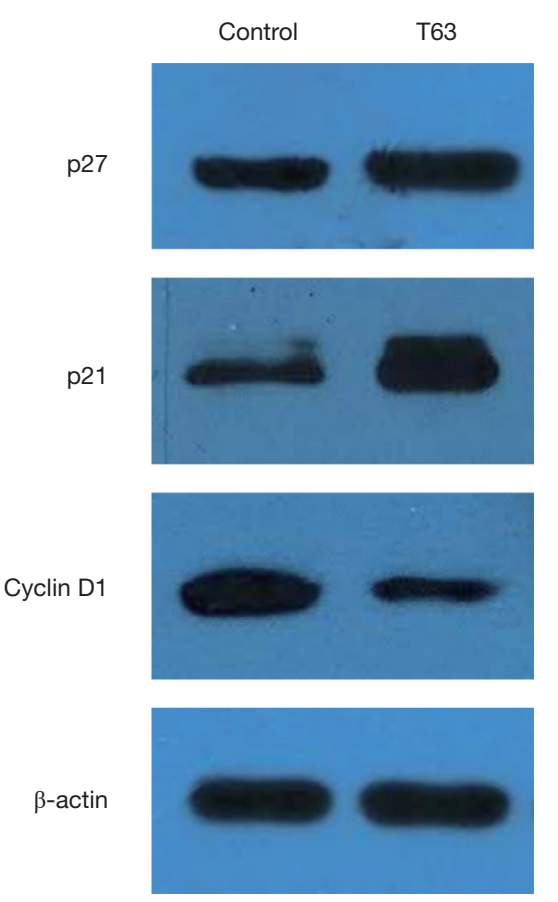

Figure 6 Expression of the p21, p27 and Cyclin D1 proteins in NPC cells treated with 10058-F4 were detected by western blotting. The levels of Cyclin D1 was found to be significantly inhibited in cells with T63, while the levels of p21 and p27 were increased.

curcumin inhibited proliferation of human gastric cancer cells by blocking the $\mathrm{G}_{2} / \mathrm{M}$ transition (13). Inhibiting cancer cells in $G_{2} / M$ phase of the cell cycle can make radiation more effective (12). We found T63 was able to promote cell cycle arrest in $G_{2} / M$ phase. But, no significant differences were found between CNE2 and CNE2R cells. As reported, the $G_{2} / M$ phase was related to DNA synthesis and the mitotic preparation period, and $\mathrm{G}_{2} / \mathrm{M}$ arrest led potentially to apoptosis (14). Therefore, the effect of apoptosis might partly be associated with T63's ability to block cells in $G_{2} / M$ cell cycle phase. Our results showed a significant increase in apoptosis by AnnexinV-FITC/PI double staining, especially in CNE2R cells. It indicated T63 might be a potential anticancer drug for radioresistant NPC cells. Furthermore, we observed the morphological changes of NPC cells upon T63 treatment. All data demonstrated the pro-apoptotic effect of T63 on both radiosensitive and radioresistant NPC cells.

The mitochondria-mediated apoptosis pathway is referred to as the intrinsic apoptosis pathway, and it plays a central role in apoptosis induced by the caspase- dependent pathway (15). Our results showed that one of the early events in the apoptotic process induced by T63 was mitochondrial depolarization and loss of mitochondrial membrane potential in CNE2 and CNE2R cells, and the changes in CNE2R were more obvious than in CNE2 cells $(\mathrm{P}<0.05)$ (Figure $3 C)$. Apoptosis stimuli can cause mitochondrial membrane potential loss and cytochrome-c release from the mitochondria to the cytosol (16). We detected cytochrome-c in the cytosol increased in a dose-dependent manner (Figure 4). Then in the cytosol, cytochrome-c activates caspase-3, after which specific substrates of caspase-3, such as PARP, are cleaved, eventually leading to apoptosis. To evaluate the apoptotic effect of T63, we detected some caspases, including caspase-8, caspase- 9 and caspase- 3 and cleaved PARP. Previous study reported that caspase- 8 was the initiator of the death receptor pathway (17), and involved in mitochondriamediated apoptosis via caspase-9 was the initiator of the mitochondrial-mediated apoptotic pathway (18). The PARP is the substrate for some caspases during apoptosis, which involved in DNA repair, genome surveillance, and maintenance of genomic integrity in response to environmental stress. Its cleaved protein is considered as an important biomarker of apoptosis. Moreover, caspase-3 is considered to be the central effector protein in the execution of apoptosis by cleaving PARP (19). Our results showed the decreases of procaspase- 8 , procaspase- 9 and the increases of cleaved caspase- 8 and cleaved caspase- 9 in both CNE2 and CNE2R cells after treatment with T63 for $48 \mathrm{~h}$. We also found the decrease of procaspase- 3 and increase of cleaved caspase- 3 and cleaved PARP (Figure 4). These results demonstrated that T63 can effectively induced apoptosis through mitochondria-mediated apoptosis pathway by activation of caspase proteins. Bcl-2 are key regulators of the mitochondria-mediated apoptosis. It is notable that T63 significantly decreased the expression levels of the anti-apoptotic Bcl-2 protein, and increased the expression levels of pro-apoptotic Bax proteins (Figure 5).

In order to explore the concrete apoptotic pathway of T63 pro-apoptotic effect, we detected the alteration of mitochondrial membrane potential and two important proteins PTEN and Akt on PI3K/Akt signaling pathway. PI3K/Akt is one of the most important signaling pathways in regulating cell proliferation, growth, apoptosis, survival and metabolism by phosphorylating a variety of substrates, and the inhibition of Akt phosphorylation has been suggested as a novel targeted for the rapeutic agents in human cancer (20). Ou et al. demonstrated that 
radioresistance reduced in NPC involving Akt pathway (21). And it was reported that curcumin sensitized tumors to gamma radiation by down-regulating various growth regulatory pathways and specific genetic targets including Akt (4). PTEN is a well-known tumor suppressor gene mutated in a large number of cancers at high frequency, containing a tensin-like domain and a catalytic domain. Generally, PTEN acts as tumor suppressor by negatively regulating the Akt signaling pathway (22). The deregulation of PTEN contributes to tumor genesis, metastasis, and proliferation $(23,24)$. To explore the role of Akt in proapoptotic effect of T63 on NPC cells especially of radioresistant NPC cells, we further detected the level of $\mathrm{p}-\mathrm{Akt}^{\mathrm{p}}{ }^{\mathrm{473}}$ and total Akt. We demonstrated that T63 directly targeted PTEN and promoted PTEN expression levels in CNE2 and CNE2R cells. And T63 inhibited the levels of $\mathrm{p}-\mathrm{Akt}^{\mathrm{p} 773}$ in a dose-dependent manner, which is similar with previous report (10). We demonstrated that PTEN was downregulated in NPC cells and directly targeted by T63, suggesting that the positive role of T63 in NPC cells may be represented by the down-regulation of the PI3K/Akt pathway.

The changes of Bcl-2/Bax accompanied by an arrest of cell cycle progression and apoptosis induction can be increased by the $\mathrm{p}-\mathrm{Akt}^{\mathrm{p} 473}(25)$. In response to the drug, the Bcl-2 family proteins congregate at intracellular membranes to adjudicate whether the cell should die, which are the hallmark of apoptosis regulation (26). Bax was shown to induce cell death, while Bcl-2 protected cell death from mitochondrial disruption (27). Bcl-2 protein family is possibly related to cancer pathophysiology and resistance to conventional chemotherapy and radiotherapy. Alternations in expression of the Bcl-2 family members could play a significant role in cell death (28). In our study, we found that the apoptotic protein Bax increased and the anti-apoptotic protein $\mathrm{Bcl}-2$ decreased leading to a decrease in Bcl-2/Bax ratio (Figure 5), which was the key event for apoptosis due to loss of mitochondrial potential and mitochondrial release cytochrome-c into the cytosol in CNE2 and CNE2R cells $(28,29)$.

\section{Conclusions}

We demonstrated that T63 definitely induced apoptosis in both radiosensitive and radioresistant NPC cell lines. Furthermore, we found that T63 induced apoptosis mainly through mitochondrial dysfunction. We also suggested PI3K/Akt signaling pathway might be important effectors in the anticancer role of T63. Although the pathways involving with apoptosis were similar between CNE2 and CNE2R cells, the effect of mitochondria-mediated apoptosis was stronger on radioresistant cells than that on radiosensitive cells. In conclusion, T63 might be a promising anticancer drug for NPC treatment, especially for radioresistant NPC cells.

\section{Acknowledgments}

We thank professor Bu (School of Pharmaceutical Sciences, Sun Yat-sen University) for the drug.

Funding: This work is supported by the National Natural Science Foundation of China $(81071837$; 30670627); the Science and Technology Funding Project of Guangzhou, China (No. 2009Z1E2012).

\section{Footnote}

Data Sharing Statement: Available at http://dx.doi. org/10.21037/tcr-20-1677

Conflicts of Interest: All authors have completed the ICMJE uniform disclosure form (available at http://dx.doi. org/10.21037/tcr-20-1677). The authors have no conflicts of interest to declare.

Ethical Statement: The authors are accountable for all aspects of the work in ensuring that questions related to the accuracy or integrity of any part of the work are appropriately investigated and resolved.

Open Access Statement: This is an Open Access article distributed in accordance with the Creative Commons Attribution-NonCommercial-NoDerivs 4.0 International License (CC BY-NC-ND 4.0), which permits the noncommercial replication and distribution of the article with the strict proviso that no changes or edits are made and the original work is properly cited (including links to both the formal publication through the relevant DOI and the license). See: https://creativecommons.org/licenses/by-nc-nd/4.0/.

\section{References}

1. Pan Y, Zhang Q, Tian L, et al. Jab1/CSN5 negatively regulates p27 and plays a role in the pathogenesis of nasopharyngeal carcinoma. Cancer Res 2012;72:1890-900.

2. Elser C, Siu LL, Winquist E, et al. Phase II trial of 
sorafenib in patients with recurrent or metastatic squamous cell carcinoma of the head and neck or nasopharyngeal carcinoma. J Clin Oncol 2007;25:3766-73.

3. Rashmi R, Kumar S, Karunagaran D. Ectopic expression of Hsp70 confers resistance and silencing its expression sensitizes human colon cancer cells to curcumin-induced apoptosis. Carcinogenesis 2004;25:179-87.

4. Goel A, Aggarwal BB. Curcumin, the golden spice from Indian saffron, is a chemosensitizer and radiosensitizer for tumors and chemoprotector and radioprotector for normal organs. Nutr Cancer 2010;62:919-30.

5. Veeraraghavan J, Natarajan M, Lagisetty $P$, et al. Impact of curcumin, raspberry extract, and neem leaf extract on rel protein-regulated cell death/radiosensitization in pancreatic cancer cells. Pancreas 2011;40:1107-19.

6. Zhongfa L, Chiu M, Wang J, et al. Enhancement of curcumin oral absorption and pharmacokinetics of curcuminoids and curcumin metabolites in mice. Cancer Chemother Pharmacol 2012;69:679-89.

7. López-Lázaro M. Anticancer and carcinogenic properties of curcumin: considerations for its clinical development as a cancer chemopreventive and chemotherapeutic agent. Mol Nutr Food Res 2008;52 Suppl 1:S103-27.

8. Qiu X, Du Y, Lou B, et al. Synthesis and Identification of New 4-Arylidene Curcumin Analogues as Potential Anticancer Agents Targeting Nuclear Factor-kappaB Signaling Pathway. J Med Chem 2010;53:8260-73.

9. Liu H, Zhou BH, Qiu X, et al. T63, a new 4-arylidene curcumin analogue, induces cell cycle arrest and apoptosis through activation of the reactive oxygen species-FOXO3a pathway in lung cancer cells. Free Radic Biol Med 2012;53:2204-17.

10. Liu H, Liu YZ, Zhang F, et al. Identification of potential pathways involved in the induction of cell cycle arrest and apoptosis by a new 4-arylidene curcumin analogue T63 in lung cancer cells: a comparative proteomic analysis. Mol Biosyst 2014;10:1320-31.

11. Lin Y'T, Wang LF, Hsu YC. Curcuminoids suppress the growth of pharynx and nasopharyngeal carcinoma cells through induced apoptosis. J Agric Food Chem 2009;57:3765-70.

12. Khafif A, Hurst R, Kyker K, et al. Curcumin: a new radiosensitizer of squamous cell carcinoma cells. Otolaryngol Head Neck Surg 2005;132:317-21.

13. Koo JY, Kim HJ, Jung KO. Curcumin inhibits the growth of AGS human gastric carcinoma cells in vitro and shows synergism with 5-fluorouracil. J Med Food 2004;7:117-21.

14. Teodoro AJ, Oliveira FL, Martins NB, et al. Effect of lycopene on cell viability and cell cycle progression in human cancer cell lines. Cancer Cell Int 2012;12:36.

15. Son YO, Hitron JA, Wang X, et al. Cr(VI) induces mitochondrial-mediated and caspase-dependent apoptosis through reactive oxygen species-mediated p53 activation in JB6 Cl41 cells. Toxicol Appl Pharmacol 2010;245:226-35.

16. Wei MC, Zong WX, Cheng EH, et al. Proapoptotic BAX and BAK: a requisite gateway to mitochondrial dysfunction and death. Science 2001;292:727-30.

17. Lee CS, Jang ER, Kim YJ, et al. Diarylheptanoid hirsutenone enhances apoptotic effect of TRAIL on epithelial ovarian carcinoma cell lines via activation of death receptor and mitochondrial pathway. Invest New Drugs 2012;30:548-57.

18. Conradt B, Horvitz HR. The C. elegans protein EGL-1 is required for programmed cell death and interacts with the Bcl-2-like protein CED-9. Cell 1998;93:519-29.

19. Enari M, Talanian RV, Wong WW, et al. Sequential activation of ICE-like and CPP32-like proteases during Fas-mediated apoptosis. Nature 1996;380:723-6.

20. DeGraffenried LA, Fulcher L, Friedrichs WE, et al. Reduced PTEN expression in breast cancer cells confers susceptibility to inhibitors of the PI3 kinase/Akt pathway. Ann Oncol 2004;15:1510-6.

21. Ou J, Pan F, Geng P, et al. Silencing fibronectin extra domain A enhances radiosensitivity in nasopharyngeal carcinomas involving an FAK/Akt/JNK pathway. Int J Radiat Oncol Biol Phys 2012;82:e685-91.

22. Parsons DW, Wang TL, Samuels Y, et al. Colorectal cancer: mutations in a signalling pathway. Nature 2005;436:792.

23. Vitolo MI, Weiss MB, Szmacinski M, et al. Deletion of PTEN promotes tumorigenic signaling, resistance to anoikis, and altered response to chemotherapeutic agents in human mammary epithelial cells. Cancer Res 2009;69:8275-83.

24. Kong L, Schafer $\mathrm{G}, \mathrm{Bu} \mathrm{H}$, et al. Lamin A/C protein is overexpressed in tissue-invading prostate cancer and promotes prostate cancer cell growth, migration and invasion through the PI3K/AKT/PTEN pathway. Carcinogenesis 2012;33:751-9.

25. Palozza P, Colangelo M, Simone R, et al. Lycopene induces cell growth inhibition by altering mevalonate pathway and Ras signaling in cancer cell lines. Carcinogenesis 2010;31:1813-21.

26. Cory S, Huang DC, Adams JM. The Bcl-2 family: roles in cell survival and oncogenesis. Oncogene 
2003;22:8590-607.

27. Tzifi F, Economopoulou C, Gourgiotis D, et al. The Role of BCL2 Family of Apoptosis Regulator Proteins in Acute and Chronic Leukemias. Adv Hematol 2012;2012:524308.

28. Karmakar S, Choudhury SR, Banik NL, et al. Induction of Mitochondrial Pathways and Endoplasmic Reticulum

Cite this article as: Liu Q, Chen W, Yang H. T63 induces apoptosis in nasopharyngeal carcinoma cells through mitochondrial dysfunction and inhibition of PI3K/Akt signaling pathway. Transl Cancer Res 2020;9(8):4635-4645. doi: 10.21037/ tcr-20-1677
Stress for Increasing Apoptosis in Ectopic and Orthotopic Neuroblastoma Xenografts. J Cancer Ther 2011;2:77-90.

29. Kim H, Rafiuddin-Shah M, Tu HC, et al. Hierarchical regulation of mitochondrion-dependent apoptosis by BCL-2 subfamilies. Nat Cell Biol 2006;8:1348-58. 